\title{
The effect of class composition on cross-curricular pÿcompetences Students with special educational needs in regular classes in lower secondary education
}

\author{
Hienonen, Ninja
}

2018-12

Hienonen , N , Lintuvuori , M , Jahnukainen , M , Hotulainen , R \& Vainikainen , M-P 2018 , ' pÿThe effect of class composition on cross-curricular competences Students with special educational needs in regular classes in lower secondary education ' , Learning and Instruction, vol. 58 , pp. 80-87 . https://doi.org/10.1016/j.learninstruc.2018.05.005

http://hdl.handle.net/10138/316302

https://doi.org/10.1016/j.learninstruc.2018.05.005

cc_by_nc_nd

acceptedVersion

Downloaded from Helda, University of Helsinki institutional repository.

This is an electronic reprint of the original article.

This reprint may differ from the original in pagination and typographic detail.

Please cite the original version. 
The effect of class composition on cross-curricular competences - Students with special educational needs in regular classes in lower secondary education

Ninja Hienonen ${ }^{1}$, Meri Lintuvuori ${ }^{1}$, Markku Jahnukainen ${ }^{2}$, Risto Hotulainen ${ }^{1}$ \& Mari-Pauliina Vainikainen $^{1^{3}}$

Corresponding author: ninja.hienonen@helsinki.fi

The institutional affiliations:

${ }^{1}$ Centre for Educational Assessment,

Faculty of Educational Sciences,

University of Helsinki, Finland

P.O. Box 9, 00014 University of Helsinki, Finland

Email: ninja.hienonen@helsinki.fi Phone: +358-50-3182195

Email: meri-lintuvuori@ helsinki.fi

Email: risto.hotulainen@helsinki.fi

Email: mari-pauliina.vainikainen@helsinki.fi

${ }^{2}$ Unit of Education and Society

Faculty of Educational Sciences,

P.O. Box 9, 00014 University of Helsinki, Finland

Email: markku.jahnukainen@helsinki.fi

${ }^{3}$ Faculty of education

Åkerlundinkatu 5

33014 University of Tampere, Finland 


\begin{abstract}
This study investigates how the proportion of SEN students in regular classes is related to the class-level cross-curricular competences and to the cross-curricular competences of students with and without SEN. The data $(\mathrm{N}=5368)$ come from a large-scale, longitudinal assessment study conducted on students at the beginning and end of lower secondary education in 14 municipalities in a Finnish metropolitan area. The results of the multilevel regression models showed that students in regular classes with SEN students performed on average lower than students in classes without SEN students, and that the proportion of students with SEN in class weakly predicted negatively the ninth-grade test scores. Furthermore, students with SEN seemed to perform at the same level regardless of the proportion of other SEN students in class. However, students without SEN in classes with SEN students performed slightly lower than their peers in classes without SEN students.
\end{abstract}

Keywords: Class composition; Special educational needs; Tiered-support model; Crosscurricular competence; Longitudinal study 


\section{Introduction}

In the present study, the class composition effect is examined in terms of the proportion of students with special educational needs in class. In general, the placement of different students into the same classroom can have an impact on academic performance measured either by school grades or test performance. It can also affect non-cognitive outcomes such as socioemotional functioning or well-being at school (i.e., Ruijs \& Peetsma, 2009; Ruijs, Van der Veen, \& Peetsma, 2010). It is evident that purposeful sorting of students into classrooms is one way of managing student diversity in schools and responding to the initial students differences (Harker \& Tymms, 2004; Kupiainen \& Hienonen, 2016). The aim of the placement practices can be to create heterogeneous and more balanced classes for example by placing students with and without SEN into the same classrooms or to form more homogenous classes and place these students into separate classrooms. Various factors affect the student placement practices in schools, such as student background, prior achievement, behavioral issues, parental requests, and previous interactions with teachers or other students (Konstantopoulos \& Traynor, 2014; Paufler \& Amrein-Beardsley, 2013). Especially when assigning students with different special educational needs into classrooms, in addition to the best interests of the students, the resources and available support as well as the best interest of teachers are taken into consideration (Jahnukainen, 2015).

In Finland, the differences between classes is relatively high, accounting on average for 10 to 15 percent of the variation in different test achievement (Thuneberg, Hautamäki, \& Hotulainen, 2015; Yang Hansen, Gustafsson, \& Rosén, 2014). In many school-effect studies, achievement differences are found to be related to differences in the composition of the student body (Harker \& Tymms, 2004). The same mechanism can be assumed to apply to class-level differences as well, partly due to non-random student assignment practices.

There is much debate about what would be the optimal proportion of students with SEN in a certain class: often strong opinions are presented with contradictory or little evidence. The 
present study examines how class composition, in terms of the proportion of students with SEN, predicts the students' cross-curricular competences at the class level. It also examines, how this proportion is related to the cross-curricular competences of students with and without SEN. We use the term 'students with SEN' of students who receive Tier 2 or Tier 3 level support according to the Finnish three-tiered support model described in Section 1.1. For students who do not receive Tier 2 or Tier 3 support, we use the term 'students without SEN.' However, they may receive Tier 1 support. Furthermore, this study focuses on regular classes and we use the term 'regular classes with SEN students' when referring to the classes where there is at least one student receiving Tier 2 or Tier 3 support. To distinguish, other classes are referred as 'regular classes without SEN students.'

\subsection{Multi-tiered support model in Finland}

In Finland, the special education system is referred to as Learning and schooling support and it has been based on three tiers since 2011 (Basic Education Act 628/1998 Amendment 642/2010). The system is based on the observed educational needs, not on a medical diagnosis. The aim is to bring the support to the student rather than bring the student to the support services (Jahnukainen \& Itkonen, 2015).

The three levels are general (Tier 1), intensified (Tier 2), and special (Tier 3) support. The support methods and tools are almost the same at all tier levels; however, the intensity of the provided support increases from one level to the next (FNBE, 2016; Thuneberg et al., 2013). Tier 1 general support is targeted to the whole student population; hence, official statistics are not compiled. Tier 2 intensified support is implemented when a student needs a longer period of support, or more intense support. A total of $9 \%$ of comprehensive school students received Tier 2 support alongside mainstream education. Tier 3 special support consists of the whole continuum of special education services and an administrative decision as well as an individual education plan (IEP) is always required. A total of $7.5 \%$ of all comprehensive school students received Tier 3 support in regular classes, special classes, or 
special schools (OSF, 2017). In the present study, we use the term students with SEN of all Tier 2 and 3 students even though not all Tier 2 students have actual disabilities. This is in accordance with the ISCED definition for SEN student defined by the additional support provided to their education (UNESCO, 2012).

\subsection{The placement of students with SEN}

As education providers, Finnish municipalities handle practical teaching arrangements and are responsible for the effectiveness and quality of education in their districts (FNBE, 2016). There are no regulations governing mainstream education class size and schools determine how to assign students to classrooms.

From a legislative perspective, all comprehensive school students are in the same education system (Basic Education Act 628/1998; FNBE, 2016). This is in line with the United Nations' Convention on the Rights of Persons with Disabilities (2006). Tier 2 support is provided as a part of mainstream education using flexible teaching arrangements. Thus, from a normative perspective, they should always be placed in regular classes. Tier 3 support is "provided, allowing for the pupil's interests and the facilities for providing the education, in conjunction with other instruction or partly or totally in a special-needs classroom or some other appropriate facility" (Basic Education Act 628/1998, 17 §). In 2016, of all comprehensive school students, $2.1 \%$ were taught fully in special education classes in mainstream schools and $0.7 \%$ in special schools (OSF, 2016). The idea of a least restrictive environment often underpins such decisions; nevertheless, totally inclusive schools are rare in Finland (Jahnukainen, 2015). According to the Basic Education Decree (852/1998), in education given to students receiving Tier 3 special support, the teaching group may consist of a maximum of ten Tier 3 students. In the present study, special education classes are excluded from the analyses; thus, Tier 3 students in our data are either fully or partly integrated into the regular classes, which in this study are called 'regular classes with SEN students.' 
The support and guidance, needed by the student, is defined for Tier 2 students in an Individual Learning Plan and for Tier 3 students in an Individual Education Plan. At all tier levels, support can be given as a part of mainstream education by co-teaching, remedial teaching, or part-time special education. Furthermore, at the Tier 3 level, support can be provided as temporal individual or small group learning, or support can be arranged partly or totally in special education classes. Available resources and support in school define the placement of SEN students along with the student's individual needs (FNBE, 2016; Jahnukainen, 2015). In general, in the current support system, support is provided more in regular classes and in that sense, "It is fair to state that Finnish education is special for all: When a classroom or subject-teacher co-teaches with a special education teacher, it involves all the students besides the individuals who have been identified as being in need of support. (Thuneberg et al., 2013, p. 71)"

\subsection{Class composition effect}

The term 'compositional effect' is used when a class-level aggregate of a student-level variable makes an independent contribution to the explanation of outcome variance (Harker \& Tymms, 2004). In other words, classroom composition affects the achievement of an individual student (Zimmer \& Toma, 2000). The possible class composition effect exists partly due to the purposeful sorting of students into classrooms. One explanation for the compositional effect is that two students with a similar initial level, but who are placed in different classes can be predicted to have different achievements depending on the average achievement level of their classmates. One assumption is that a student will make more progress if the average ability level of the class is higher; conversely, a student will make less progress if there are more lowperforming students with support needs in the class (Belfi, Goos, De Fraine, \& Van Damme, 2012; Peetsma, van der Veen, Koopman, \& van Schooten, 2006). Student placement practices are always choices between creating either more heterogeneous or more homogenous classrooms. It can also be assumed that teaching a homogeneous a group of students is more 
efficient than teaching a class of more heterogeneous students who have diverse support needs (Belfi et al., 2010).

When a student with SEN is placed in a regular class, the effects on the academic achievement of other students can be either positive, negative, or neutral. Furthermore, even within one study, the effects have been highly variable between schools and classes (Dyson, Farrell, Polat, Hutcheson, \& Gallannaugh, 2004; Huber, Rosenfeld, \& Fiorello, 2001). By and large, there seem to be clearly more positive than negative effects, but for the most part, the effects are neutral when both the cognitive and non-cognitive outcomes are considered (i.e., Hanushek, Kain, \& Rivkin, 2002; Kalambouka, Farrel, Dyson, \& Kaplan, 2007; Rouse \& Florian, 2006; Ruijs, 2017; Ruijs \& Peetsma, 2009; Ruijs, van der Veen et al., 2010). This can be explained by the differential effects: when for one class the effect is positive and for another negative, the average will be neutral (Ruijs \& Peetsma, 2009).

For students with SEN, studying in regular classes might be beneficial because they can learn from more able peers, yet they may feel less motivated and more insecure about their own achievement if they compare themselves to their higher-achieving peers (Belfi et al., 2010; Ruijs \& Peetsma, 2009). According to a review study conducted by Ruijs and Peetsma (2009), there are indeed indications that students with SEN achieve better in inclusive settings than in non-inclusive settings. On students without SEN, learning together with SEN students can have negative effects, if the general standard of education in the class is lowered due to more lowperforming students (Huber et al., 2001; Peetsma et al., 2006) or if the teacher expectancy is low for the whole class (Goldenberg, 1992). Furthermore, teacher may pay more attention to the students with SEN, which requires other students to study more independently (Dyson et al., 2004; Ruijs, 2017). However, according to previous research, the additional support given to a lower performing students can indirectly enhance the performance of the whole class (Dyson et al., 2004; Thuneberg et al., 2013). Quite often these compositional effects are examined with a cross-sectional design. The present study utilizes longitudinal data to control 
for the initial differences between students as these may tell more about classroom assignment practices than actual compositional effects.

In the present study, the general performance level of different classes as well as the class composition effects on performance are studied by using learning to learn assessment tasks measuring cognitive competences that are enhanced through formal subject-specific education. The assessed skills are related to curricular content, but they require the application of both effort and higher-order thinking skills instead of the repetition of subject-specific knowledge (Vainikainen, Hautamäki, Hotulainen, \& Kupiainen, 2015). They do not fall into any particular school subject; rather they are seen as common pedagogical goals for all school subjects (Hautamäki \& Kupiainen, 2014). Students are given novel tasks that they are invited to accept as their own and to apply general procedures that were acquired earlier to adapt to a new task. We use the term cross-curricular competence when referring to these assessment tasks.

\subsection{Research questions and hypotheses}

The research questions investigated in this study are:

Q1: How does class composition, in terms of the proportion of students with SEN, predict the students' cross-curricular competences at the class level?

H1: The increased proportion of students with SEN predicts negatively the general performance level of the class as students with SEN perform lower. However, the effect is not strong, due to the possible additional resources and support available in regular classrooms with SEN students (Ruijs, 2017).

Q2: When students with SEN are placed in regular classes, is the effect on students' cross-curricular competences different for students with SEN than for students without SEN?

$\mathrm{H} 2$ : The effect is more positive on students with SEN as they can learn from their more able peers (Ruijs \& Peetsma, 2009), whereas for students without SEN, the effect is less positive (Zimmer \& Toma, 2000), especially if they are distracted by the students with SEN 
(Ruijs \& Peetsma, 2009) and if the general standards of the class are lowered (Huber et al., 2001).

\section{Method}

\subsection{Participants}

The present study uses data from the Metropolitan Longitudinal study in Finland, conducted in lower-secondary schools in 14 municipalities in the Helsinki Metropolitan Area. The first phase of the data collection was conducted in autumn 2011, at the beginning of the lower secondary education at seventh grade $(\mathrm{N}=10364)$ and the second phase, with the same students, in spring 2014, at the end of lower secondary education at ninth grade $(\mathrm{N}=9441)$. The ethical approval for data collection has been obtained from the Ethical Committee of the National Institute of Health and Welfare. The permission to enter the schools was obtained from the Education Department of each municipality for both data collections. Two municipalities required parents' permission for their child's participation in 2011 and one in 2014. In the other municipalities, parents were informed of the study.

The students completed the same questionnaires at both stages including the used cognitive measures. The data used in this study consist of assessments completed by students at both stages of the study, and for whom the information on SEN status was available. SEN was measured at the ninth grade by asking special education teachers to complete the questionnaire about information on whether student received support $(\mathrm{N}=6261)$. The information was not available for 554 students and they were excluded from the analyses. With these criteria, data consisted of 256 Tier 2 students and 144 Tier 3 students. Descriptive statistics on students with SEN and without SEN are reported in Appendix A.

According to the measure for class size, which was extracted from the original ninthgrade student lists received from the Education Departments of the municipalities, there were 63 classes in which the class size was fewer than 11 students These classes were likely special education classes; thus, they (in total 294 students) were excluded from the analyses. 
Furthermore, there were 144 classes with fewer than 10 students present at the time of the assessment and they were thus also excluded (in total 771 students) from the analyses as their class-level results were not representative.

The final number of students in the further analyses was 5368 students (49.8\% girls) in 359 classes in 96 schools. Of the students with SEN, 60.8\% were boys, and of students without SEN $48.9 \%$ were boys. The mean age of students at the time of the ninth-grade data collection was 15.9 years $(S D=.33)$.

\subsection{Measures}

\section{Cross-curricular competences}

Teachers conducted both data collections according to written instructions during an ordinary school day. The assessment at the seventh grade was done using paper and pencil, and at the ninth grade using an online format. According to previous assessments, paper and online versions are comparable as the difference between them have been relatively small (Hautamäki, Kupiainen, Marjanen, Vainikainen, \& Hotulainen, 2013).

Three different cognitive tasks measured students' cross-curricular competences. Verbal proportional reasoning was assessed by seven items from the Missing Premises task of the Ross Test of Higher Cognitive Processes (Ross \& Ross, 1979). The students were given one premise and the conclusion, and they had to choose from among five alternatives the second premise which would make the conclusion valid. The items were scored dichotomously as correct or incorrect. Quantitative reasoning was assessed by seven items based on the Invented Mathematical Concepts task (Sternberg, Castejon, Prieto, Hautamäki, \& Grigorenko, 2001). Two invented arithmetical operators were conditionally defined and after the definition, the students had to select the correct answer from among four multiple choice alternatives to seven items. The items were coded dichotomously for the whole equation. Formal thinking was measured by the Control of Variables task, which is a modified version (Hautamäki, 1984) of Shayer's Science Reasoning Task 'Pendulum' (1979). The students were presented with 
comparisons sets in the world of Formula 1 races with different variables and they had to judge whether the single effect of a variable could be concluded from the comparison. All eight items were coded dichotomously for a correct answer to all the variables in the item. For the analyses, a mean for the percentage of correctly solved items waswas calculated based on the 22 items. The reliabilities were acceptable (Cronbach's $\alpha=.84$ at grade 7, and Cronbach's $\alpha=.87$ at grade 9). The measure for cross-curricular competences correlated positively with the Grade Point Average (GPA) $(r=.58, p<.001)$ at the end of lower-secondary education (GPA was calculated as a mean for all ten theoretical subjects, grades were derived from the National Joint Application Register).

\section{Student variables}

To confirm that the SEN status had an independent effect, the socioeconomic (SES) background of students was also considered, as the SES composition of a classroom can affect achievement independently of students' prior achievement (Rjosk et al., 2014). A Finnish study has shown that special educational needs are related to a lower educational background level (Kirjavainen, Pulkkinen, \& Jahnukainen, 2014). In the present study, SES was measured by mothers' educational level as an ordered categorical variable ( 1 = basic education, $19.8 \%$ of students; 2 = high school, $35.4 \%$ of students, and $3=$ polytechnic or university, $44.8 \%$ of students). Age was added as a control as research indicates that students that are young for their grade are more likely to identify with SEN (Lindsay \& Strand, 2016).

\section{Class variables}

The class composition measure was calculated by aggregating the received support to the class level as a mean percentage of the Tier 2 and Tier 3 students. Descriptive statistics for class level are reported in Appendices B and C.

\subsection{Statistical methods}

Descriptive statistics and group comparisons were calculated with SPSS24. Structural equation modeling (SEM) was applied in MPlus 7.2 (Muthén \& Muthén, 2012) to take the 
nested structure of the data into account. We specified a two-level regression model. In Model 0 , the variance was divided to the individual level and the school level. In Model 1 , at the student level, we predicted the ninth-grade test scores by the grand mean centered seventhgrade test scores, age and by dichotomously coded SEN $(0=$ no SEN, $1=$ Tier 2 or Tier 3$)$. At the class level, we used the aggregated seventh grade test performance and dichotomously coded class-level SEN $(0=$ without SEN, $1=$ with SEN) as predictors. In Model 2, we replaced the dichotomously coded class-level SEN with the proportion of SEN students in class (mean for all Tier 2 and Tier 3 students, 0-100\%). In Model 3, we studied the cross-level interaction by defining a random slope for the class-level proportion of students with SEN on received support. In Model 4, we defined the cross-level interaction in which student-level SEN status was interacted with class-level proportion of SEN students.

The deviation from normality of all variables was within the recommended limits. Models were calculated by using the Maximum Likelihood Robust (MLR) all without imputation of missing values. The goodness-of-fit of the estimated Models was evaluated by Akaike information criterion (AIC), Bayesian information criterion (BIC), and adjusted Bayesian information criterion (aBIC). The estimates for Models 1, 2 and 4 are reported as standardized regression coefficients $(\beta)$ and correlation coefficients $(r)$, and for Model 3 as unstandardized regression coefficients $(B)$ and covariates (cov).

\section{Results}

Descriptive statistics were first calculated for all variables used in modeling and they are presented in Table 1. 
Table 1.

Descriptive statistics for the variables used in modeling

\begin{tabular}{lrrrrr}
\hline Variable & $\boldsymbol{N}$ & Min & Max & $\boldsymbol{M}$ & Sd \\
\hline Test score 9th grade & 5398 & 0.00 & 100.00 & 49.84 & 23.72 \\
Within level predictor & & & & & \\
\hline Test score 7th grade & 5398 & 0.00 & 100.00 & 44.38 & 21.94 \\
Age & 5367 & 14.58 & 18.08 & 15.9 & 0.32 \\
Between level predictors & & & & & \\
\hline Test score 7th grade (class average) & 359 & 16.56 & 77.51 & 43.49 & 10.12 \\
Test score 9th grade (class average) & 359 & 21.13 & 87.00 & 49.71 & 11.39 \\
Proportion of Tier 2 and Tier 3 students (\%) & 359 & 0.00 & 50.00 & 7.50 & 8.84 \\
\hline
\end{tabular}

$N=$ Number of responses, $\operatorname{Min}=$ Minimum value, $\operatorname{Max}=$ Maximum value, $M=$ Mean, $S d=$ Standard deviation

*There were 14 students in $7^{\text {th }}$ grade and 11 students in $9^{\text {th }}$ grade who did not answer any item correctly.

The data contained 359 classes. In 160 classes, there was at least one Tier 2 student and in 111 classes there was at least one Tier 3 student. Altogether, in 210 classes there were students with SEN. The average proportion of students with SEN in these classes was $12.82 \%$ $(S D=8.07)$. Tier 2 students were placed in classes with an average of 19.89 students, and Tier 3 students were in classes with an average of 20.15 students. Students without SEN studied in classes with an average class size of 20.51 students. According to one-way ANOVA with Bonferroni post-hoc comparison, the only significant class size difference was between Tier 2 students and students without $\operatorname{SEN}(F(2,5365)=6.555, d f=2, p<.01)$. Tier 2 support and class size correlated negatively $(r=-.13, p .<.001)$ as well as Tier 3 and class size $(r=-.06, p$. $<.001)$. It must be kept in mind though, that the small special education classes with mostly Tier 3 students were excluded from the data.

\subsection{Hypothesis 1}

The intra-class correlation for the Model 0 was 0.18 , meaning that $18 \%$ of the variance in the ninth-grade test scores was accounted for by the differences between classes. After concluding that there was enough variance at a class level, both student-level and class-level variables were added to the model (Table 2). 
Table 2.

Effects for student and class variables

\begin{tabular}{|c|c|c|c|c|c|c|c|c|}
\hline & \multicolumn{2}{|l|}{ M1 } & \multicolumn{2}{|l|}{ M2 } & \multicolumn{2}{|l|}{ M3 } & \multicolumn{2}{|l|}{ M4 } \\
\hline & $\beta$ & $S E$ & $\beta$ & $S E$ & $B$ & $S E$ & $\beta$ & $S E$ \\
\hline \multicolumn{9}{|l|}{ Student-level variables } \\
\hline 7th grade test score & $0.58 * * *$ & 0.01 & $0.58 * * *$ & 0.01 & $0.58 * * *$ & 0.01 & $0.57 * * *$ & 0.01 \\
\hline SEN status & $-0.08 * * *$ & 0.01 & $-0.08 * * *$ & 0.01 & & & $-0.13 * * *$ & 0.20 \\
\hline Age & $-0.03 * *$ & 0.01 & $-0.02 * *$ & 0.01 & $-2.28 * *$ & 0.71 & $-0.03 * *$ & 0.10 \\
\hline \multicolumn{9}{|l|}{ Class-level variables } \\
\hline 7th grade test score & $0.23 * *$ & 0.07 & $0.21 * *$ & 0.07 & $0.59 * * *$ & 0.01 & $0.20 * * *$ & 0.07 \\
\hline SEN status & $-0.09 \mathrm{~ns}$ & 0.06 & & & & & & 0.06 \\
\hline SEN $\%$ & & & $-0.15^{*}$ & 0.06 & $-0.16 * *$ & 0.05 & $-0.19 * *$ & 0.06 \\
\hline Slope SEN student & & & & & $0.27 * * *$ & 0.07 & & \\
\hline SEN status*SEN\% & & & & & & & $.06 * *$ & 0.02 \\
\hline \multicolumn{9}{|l|}{ Fit indices } \\
\hline AIC & 101500.465 & & 103568.000 & & 98340.936 & & 103606.875 & \\
\hline $\mathrm{BIC}$ & 101645.401 & & 103712.936 & & 98472.696 & & 103751.812 & \\
\hline $\mathrm{aBIC}$ & 101575.492 & & 103643.027 & & 98409.142 & & 103681.903 & \\
\hline
\end{tabular}

Notes: 7th grade test scores and age are grand mean centered.

Parameter estimations are standardized in Models 1, 2 and 4 and unstandardized in Model 3.

$\mathrm{AIC}=$ Akaike information criterion, $\mathrm{BIC}=$ Bayesian information criterion and $\mathrm{aBIC}=$ adjusted Bayesian information criterion

$* \mathrm{p}<0.05, * * \mathrm{p}<0.01, * * *, \mathrm{p}<0.001, \mathrm{~ns} .=$ non-significant

The seventh-grade test score predicted ninth grade test scores statistically significantly $(\beta$ $=.58, p<.001)$ and it explained $37 \%$ of the student level differences in Model 1 . The SEN status $(\beta=-.08, p<.001)$ and age $(\beta=-.03, p<.01)$ were both negative predictors of the later test performance. The SEN status correlated negatively with seventh-grade test score $(r=-.22$, $p<.001)$ and with age $(r=-.09, p<.001)$, indicating that students with SEN performed lower at the seventh-grade test and that the older students were more likely SEN students. All the bivariate correlations for student level variables are depicted in Appendix D.

The average seventh-grade test performance at the class level predicted the ninth-grade test performance relatively well $(\beta=.23, p<.01)$, explaining $7 \%$ of the class-level test score variance. The dichotomous variable for classes with and without SEN students was nonsignificant predictor $(\beta=-.09, n s$. $)$ of the ninth-grade test performance. Nevertheless, it correlated negatively with seventh-grade test performance $(r=-.32, p<.001)$. 
In Model 2, the dichotomous variable for class-level SEN was replaced by the average proportion of students with SEN. It predicted negatively the ninth-grade test scores $(\beta=-.15, p$ $<.05)$ and correlated negatively with the seventh-grade test scores $(r=-.32, p<.001)$. All the other effects remained stable (Table 2). At this stage of the model, 36\% of student level variation and $10 \%$ of the class level variation was explained by the added variables. The fit indices of Model 1 were slightly better than the fit indices of Model 2, indicating that Model 1 with dichotomous class-level SEN status fitted the data better. All the fit indices are depicted in Table 2.

To confirm that the SEN status had an independent effect, we added the SES status to the model at both the student level and as an aggregated class level mean to the class level. At the student level, it was a statistically significant, yet not very strong $(\beta=.06, p<.001)$ predictor of ninth-grade test scores. It was also added to the model without the student level SEN measure, but the estimate did not change. At the class level, it was not a statistically significant predictor $(\beta=.05, \mathrm{~ns})$, and it was removed from the model on both levels.

To test the hypothesis further, we studied the cross-level interaction by defining a random slope for the class-level proportion of students with SEN on received support for Model 3. First, the slope was added to the model without the class-level, seventh-grade test score. The effect of the proportion of students with SEN varied across classes $(B=.36, p .<.001)$ showing that the higher the share of students with SEN in a class, the stronger the effect of received support on ninth-grade test scores. At the same time, the covariance of the ninth-grade classlevel test score variance and the slope was negative (-35.35) and significant at the .01 level, meaning that the stronger the effect of the proportion of students with SEN, the lower the performance level of the class. When it was controlled for that the average performance level of the class was lower in classes with SEN students, the effect of the proportion of students with SEN on the slope decreased $(B=.27, p .<.001)$. The fit indices of Model 3 with the random slope had the best model fit. 
The cross-level interaction of the proportion of SEN students in class and the SEN status is depicted in Figure 1. Due to the skewness of the SEN variable, the proportion of SEN students was divided to quartiles. It shows that the performance level of students without SEN slightly decreased when the proportion of students with SEN increased. However, this may tell more about student assignment practices than actual class composition effects.

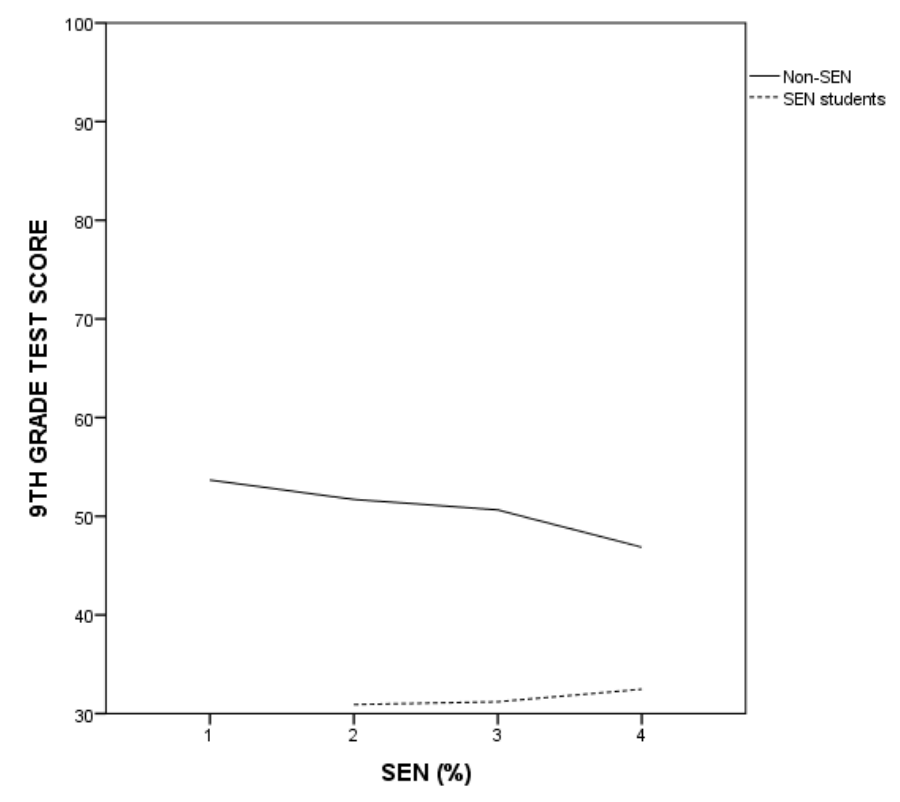

Figure 1.

The 9th grade test scores of students with and without SEN in classes with different proportion of SEN students (SEN\%). The proportion of SEN is divided to quartiles.

It was concluded that our first hypothesis was partly confirmed. The average performance level of the class was lower in classes with SEN students. The class-level SEN status as a dichotomous variable, had no statistically significant effect on ninth-grade test scores. However, as a continuous variable, the proportion of SEN students predicted negatively the general performance level of the class.

\subsection{Hypothesis 2}

In our second hypothesis, we tested if a class-level proportion of SEN students affect students with and without SEN differently. We defined a cross-level interaction between student-level SEN status and the class-level proportion of SEN students. There was a slight positive effect $(\beta=.06, p<.001)$ indicating that students with SEN are not influenced by the 
presence of other SEN students in class when their cross-curricular competences are measured. In this model, $10 \%$ of the variance in test scores was accounted for by the differences between classes. Our hypothesis was confirmed.

\section{Discussion}

The main aim of the present study was to investigate how the proportion of students with SEN in class predicted students' cross-curricular competences at class level. First, it was concluded that regular classes with SEN students performed on average lower at the beginning of the seventh grade. In Model 1, class-level SEN status was treated as a dichotomous variable, and it did not predict ninth grade test performance. This indicates that the presence of occasional Tier 2 or Tier 3 students in a class does not lower the overall performance level of a class. However, when class-level SEN status was added to Model 2 as a continuous variable, it was concluded that the proportion of students with SEN in a class predicted negatively, though weakly, the ninth-grade test scores. Furthermore, our results indicated that the higher the proportion of SEN students, the lower the ninth-grade class-level test scores. These findings may indicate implicit tracking which in turn may result in cognitively less demanding classroom settings; this can partly account for the negative effects found in Model 2. According to a previous Finnish study, the proportion of students with SEN in a class predicted greater progress in primary schools (Vainikainen, Hienonen, \& Hotulainen, 2017). As the present study showed the opposite effects at the lower-secondary education level, the support provided in regular classes should be studied more closely.

According to the Finnish support system, the aim is to provide support as a part of mainstream education whenever possible. However, there is a lack of research focusing on how the support is provided in regular classes. Previous studies suggest that the placement of students with SEN in regular schools can have a positive impact on the achievement of their mainstream peers, particularly if the support provided to the students with SEN is well managed (Cole, Waldron, \& Majd, 2004; Saint-Laurent et al., 1998). Furthermore, additional 
staff in classes with SEN students can benefit the whole class (Cole et al., 2004; Ruijs, 2017; Thuneberg et al., 2013). The weak negative effects discovered in this study might suggest that more attention should be paid to the support resources available in schools.

One of the main findings of the present study was that the proportion of students with SEN in class had a slightly different effect on cross-curricular competences for students with SEN than for students without SEN. Students with SEN seemed to perform at the same level regardless of the proportion of other SEN students in class. However, students without SEN in classes with SEN students performed slightly lower than their peers in classes without SEN students. This is consistent with the American study by Huber et al. (2001), which has shown that in inclusive settings, lower-performing students made stronger academic gains, while higher- performing students experienced decreased achievement. Then again, there are other studies, from the Netherlands, the United Kingdom, and the United States that indicate that the presence of students with SEN had no impact on the academic achievement of students without SEN (Hanushek et al., 2002; Kalambouka et al., 2007; Ruijs, 2017, Ruijs, van der Veen, et al., 2010). However, the education systems and definitions for SEN students vary across countries, making the comparison of the results challenging.

The effects found in the present study suggest something about student assignment practices. This agrees with the previous literature, the non-random sorting of students into classrooms is one way to manage student diversity in schools, especially concerning students with SEN, yet, the purposeful sorting of students is not a neutral act and can increase further the between-class differences discovered to be relatively high in Finnish schools (Thuneberg et al., 2015; Yang Hansen et al., 2014).The differences between classes may often result more from classroom assignment practices than from actual compositional effects. Although Finnish basic education is provided within a single structure without clear division into primary (grades 1-6) and lower secondary (grades 7-9) education, in many municipalities there still are separate schools for them. Therefore, students are quite often allocated to new classrooms with 
new classmates at the beginning of the seventh grade. In light of our findings, there seems to be a tendency to create more homogeneous classrooms as less-achieving students without SEN are placed together with SEN students which implies an informal tracking system. In one sense, it seems reasonable that lower performing students are grouped in classes with SEN students as this is in line with the assumption that teaching a class with more homogeneous student population is more efficient than teaching a more heterogeneous class (Belfi et al., 2010). Because of this kind of informal tracking, teachers might simply teach the lower-performing classes differently by lowering the overall attainment level of the class independent of the presence or absence of SEN students. This is also in line with previous research on teacher expectancy (Goldenberg, 1992). A teacher who has low expectations is probably less likely to present advanced material and more likely to provide less demanding material.

The importance of the present study lies partly on the longitudinal large-scale assessment data and on the multilevel analyses. We considered the nested structure of the data by distinguishing two levels in the analyses: class level and student level; thus we were able to discern compositional effects from individual differences. Nevertheless, this study has some limitations. Students with SEN form a very heterogeneous group of students. They may have very different types of special educational needs; naturally, different needs require different classroom placements and these placements may have different effects on the other students in the class. The data used in this study do not include the information of the grounds for the received support. To avoid a heavy workload for the teachers, this background information was not requested. It would have also been against the Finnish policy of avoiding diagnosis-based categorizing of SEN students. A second limitation of this study concerns the time the students spend in their classes. In lower secondary education, class composition tends to vary slightly by subject area, and therefore can vary for each student during a school day. Unfortunately, data about practices in diverse types of classrooms are not available in this study. For future research and practical implications, it would be important to collect such detailed observational 
data that could explain the mechanisms of how the compositional effects are mediated by classroom practices. A third limitation concerns the cognitive measures of the study. Contrary to many previous studies, our study used tasks measuring cross-curricular competences instead of school performance measure. However, the measure for cross-curricular competences correlated relatively strongly with the GPA.

Our study revealed that the proportion of students with SEN in class predicted slightly lower class-level, cross-curricular competences. However, we are not able to explicitly explain these effects with our data. This important line of research clearly requires more attention in the future. Concerning the performance of SEN students, the class compositional effects described in the present study are most probably mediated by the additional support provided and the presence of additional staff in class. Further research is needed on how the additional support in class is organized in general and who benefits from it. Generally, compositional effects are difficult to discern probably because they are a combination of direct and indirect effects (Wilkinson, Parr, Fung, Hattie, \& Townsend, 2002). Furthermore, in some studies, the differences in the development of educational achievement has been associated far more strongly with the characteristics of the students than with the class composition (Peetsma et al., 2006). Indeed, in our data, when the student-level SEN status was added to the model, the effect of the class-level proportion of students with SEN was decreased. Other previous literature, such as a Dutch study using cohort data from primary school has indicated contradictory results as the number of SEN students in class explained differences between students better than the student-level SEN status (Ruijs, Peetsma et al., 2010).

Students with SEN have diverse needs, and the resources to support these students vary among schools. These factors in turn affect which proportion of SEN students in class influence the overall class-level performance. According to our data, it seems that when more than a fifth of students in class are SEN students, the average performance level of class is slightly lowered. This may be explained by the above-mentioned teacher expectancy, the cognitively 
less demanding classroom setting, and by the lack of adequate resources to support the lowperforming as well as the high-performing students in class.

In any case, grouping students is not a neutral act. Depending on the basis according to which students are assigned to classrooms "differentiation for the sake of efficiency can conflict with the desire for social integration within schools (Gamoran, Nystrand, Berends, \& Lepore, 1995)." Thus, it can be reasoned that more information is needed on student assignment practices and support practices in classrooms.

\section{Conclusions}

So far, there has been no consensus in the literature of the composition effects in regular classes with SEN students. The present study is the first Finnish study to examine these effects. It showed that there are class compositional effects in terms of students with SEN in regular classes; these effects are slightly different for SEN students than for other students. In all, it seems that all students benefit from more able peers and from the higher achievement level of the class. In that sense, attention should also be paid to the students without SEN in regular classes with SEN students. As there are class-level effects, identifying and providing sufficient support as well differentiated instruction in regular classes for all students becomes important. For SEN students, adequate support for learning should be provided and at the same time, for students without SEN, teaching should meet their achievement level. Allocation of resources in terms of teaching staff becomes extremely important. When all students study together, flexible teacher arrangements and within-class grouping practices are prerequisite for any learning. The Basic Education Act (628/1998) states that education shall be provided according to the students' age and capabilities. When students at different performance levels study together, this aim should also be achieved.

\section{References}

Basic Education Act 628/1998. Amendments up to 1136/2010. Government of Finland. http://www.finlex.fi/en/laki/kaannokset/1998/en19980628.pdf/ Accessed 15.04.2017. 
Basic Education Decree 852/1998. Amendments up to 966/2016. Government of Finland. http://www.finlex.fi/fi/laki/ajantasa/1998/199808527 Accessed 15.04.2017.

Belfi, B., Goos, M., De Fraine, B., \& Van Damme, J. (2012). The effect of class composition by gender and ability on secondary school students' school well-being and academic selfconcept: A literature review. Educational Research Review, 7, 62-74. doi:10.1016/j.edurev.2011.09.002

Cole, C., Waldron, N., \& Majd, M. (2004). Academic progress of students across inclusive and traditional settings. Mental Retardation, 42, 136-44. DOI:10.1352/00476765(2004)42<136:APOSAI>2.0.CO;2

Dyson, A., Farrell, P., Polat, F., Hutcheson, G., \& Gallannaugh, F. (2004): Inclusion and pupil achievement. Research Report RR578. Newcastle: University of Newcastle.

FNBE. (2016). National Core Curriculum for Basic Education. Publications 2016:5. Helsinki: National Board of Education.

Gamoran, A., Nystrand, M., Berends, M., \& LePore, P.C. (1995). An Organizational Analysis of the Effects of Ability Grouping. American Educational Research Journal, 32, 687715.

Goldenberg, J. (1992). The Limits of Expectations: A case for case knowledge about teacher expectancy effects. American Educational Research Journal, 29, 517-544.

Hanushek, E. A., Kain J. F., \& Rivkin, S. G. (2002). Inferring program effects for special populations: Does special education raise academic achievement for students with disabilities? Review of Economics and Statistics, 84(4), 584-599.

Harker, R., \& Tymms, P. (2004). The effects of student composition on school outcomes. School Effectiveness and School Improvement, 15(2), 177-199. DOI:0.1076/sesi.15.2.177.30432 
Hautamäki, J. (1984). Peruskoululaisten loogisen ajattelun mittaamisesta ja esiintymisestä.

[Measuring and the occurrence of logical thinking among basic school students]. Joensuun yliopiston yhteiskuntatieteellisiä julkaisuja 1. Joensuu: Joensuun yliopisto.

Hautamäki, J. \& Kupiainen, S. (2014). Learning to Learn in Finland. In R. Crick, C. Stringer, \& K. Ren, (Eds.) Learning to Learn: International Perspectives from Theory and Practice (170-195). London: Routledge.

Hautamäki, J., Kupiainen, S., Marjanen, J., Vainikainen, M.-P., \& Hotulainen, R. (2013). Oppimaan oppiminen peruskoulun päättövaiheessa: Tilanne vuonna 2012 ja muutos vuodesta 2001. [Learning to learn at the end of basic education - Results in 2012 and changes from 2001] Department of Teacher of Education Research Report No 347. Helsinki: University of Helsinki.

Huber, K. D., Rosenfeld, J. G., \& Fiorello, G. A. (2001). The differential impact of inclusion and inclusive practices on high, average and low achieving general education students. Psychology in the Schools, 38(6), 497-504. doi.org/10.1002/pits.1038

Jahnukainen, M. (2015). Inclusion, integration, or what? A comparative study of the school principals' perceptions of inclusive and special education in Finland and in Alberta, Canada. Disability \& Society, 30, 59-72. DOI:org/10.1080/09687599.2014.982788

Jahnukainen, M., \& Itkonen, T. (2015). Tiered intervention: History and trends in Finland and the United States. European Journal of Special Needs Education, 31(1), 140-150. DOI: $10.1080 / 08856257.2015 .1108042$

Kalambouka, A., Farrell, P., Dyson A., \& Kaplan, I. (2007). The impact of placing pupils with special educational needs in mainstream schools on the achievement of their peers. Educational Research, 49, 365-382, DOI: 10.1080/00131880701717222

Kirjavainen, T., Pulkkinen, J. \& Jahnukainen, M. (2014). Erityisoppilaidem osuuksien kuntakohtaiseen vaihteluun vaikuttaneet tekijät vuosina 2001-2010. [Factors affecting 
municipal variation in the share of students with special educational needs in 20012010.] Yhteiskuntapolitiikka, 6, 619-630.

Kline, R. B. (2005). Principles and Practice of Structural Equation Modeling. Second edition. New York: The Guildford Press.

Konstantopoulos, S., \& Traynor, A. (2014). Class Size Effects on Reading Achievement Using PIRLS Data: Evidence from Greece. Teachers College Record, 116 (2), 1-29.

Kupiainen, S., \& Hienonen, N. (2016). Luokkakoko. [Class size]. Research in Education and Science 72. Jyväskylä: Finnish Educational Research Association.

Lindsay, G., \& Strand, S. (2016). Children with Language Impairment: Prevalence, Associated Difficulties, and Ethnic Disproportionality in an English Population. Frontiers in Education, 1(2), 1-14. doi:10.3389/feduc.2016.00002

Muthén, L. K., \& Muthén, B. O. (2012). Mplus user's guide version 7.

OSF. (2017). Special education. Helsinki: Statistics Finland. http://www.stat.fi/til/erop/index_en.html/ Accessed 23.06.2017.

Paufler, N. A., \& Amrein-Beardsley, A. (2013). The random assignment of students into elementary classrooms: implications for value-added analyses and interpretations. American Educational Research Journal, 51, 328-362. DOI:10.3102/0002831213508299

Peetsma, T., van der Veen, I., Koopman, P., \& van Schooten, E. (2006). Class Composition Influences on Pupils' Cognitive Development. School Effectiveness and School Improvement, 17, 275-302. DOI: 10.1080/13803610500480114

Rjosk C., Richte, D., Hochweber, J., Lüdtke, O., Klieme, E., \&, Stanat, P. (2014). Socioeconomic and language minority classroom composition and individual reading achievement: The mediating role of instructional quality. Learning and Instruction, 32, 63-72. doi.org/10.1016/j.learninstruc.2014.01.007

Rouse F., \& Florian, L. (2006). Inclusion and achievement: student achievement in secondary schools with higher and lower proportions of pupils designated as having special 
educational needs. International Journal of Inclusive Education, 10, 481-493. DOI: $10.1080 / 13603110600683206$

Ross, J. D., \& Ross, C. M. (1979). Ross test of Higher Cognitive Processes. Novato, CA: Academic Therapy Publications.

Ruijs, N. (2017). The impact of special needs students on classmate performance. Economics of Education Review, 58, 15-31. doi.org/10.1016/j.econedurev.2017.03.002

Ruijs, N. \& Peetsma, T. (2009). Effects of inclusion on students with and without special educational needs reviewed. Educational Research Review, 4, 67-79.

DOI:10.1016/j.edurev.2009.02.002

Ruijs, N., Peetsma, T., \& Van der Veen, I. (2010.) The presence of several students with special educational needs in inclusive education and the functioning of students with special educational needs, Educational Review, 62, 1-37. doi.org/10.1080/00131910903469551

Ruijs, N., Van der Veen, I., \& Peetsma, T. (2010). Inclusive education and students without special educational needs. Educational Research, 52, 351-390.

DOI:10.1080/00131881.2010.524749

Saint-Laurent, L., Dionne, J., Giasson, J., Royer, E., Simard, C., \& Pierard, B. (1998). Academic achievement effects of an in-class service model on students with and without disabilities. Exceptional Children, 64(2), 239-253.

Shayer, M. (1979). Has Piaget's construct of formal operational thinking any utility? British Journal of Educational Psychology, 49, 265-276. doi: 10.1111/j.20448279.1979.tb02425.x

Sternberg, R., Castejon, J. L., Prieto, M. D., Hautamäki, J., \& Grigorenko, E. (2001). Confirmatory factor analysis of the Sternberg Triarchic Abilities Test in three international samples. European Journal of Psychological Assessment, 17, 1-16. doi.org/10.1027//1015-5759.17.1.1 
Thuneberg, H., Hautamäki, J., \& Hotulainen, R. (2015). Scientific Reasoning, School Achievement and Gender: A Multilevel Study of between and within School Effects in Finland. Scandinavian Journal of Educational Research, 59(3), 337-356. DOI: $10.1080 / 00313831.2014 .904426$

Thuneberg, H., Vainikainen, M.-P., Ahtiainen, R., Lintuvuori, M., Salo, K., \& Hautamäki, J. (2013). Education is special for all: The Finnish support model. Gemeinsam leben, 2, 6778.

UNESCO. (2012). International Standard Classification of Education. ISCED 2011. UNESCO: Montreal, Quebec.

United Nations. (2006). Convention on the Rights of Persons with Disabilities. A/61/611. http://www.un.org/esa/socdev/enable/rights/convtexte.htm\#convtext. Accessed 15.12.2017.

Vainikainen, M.-P., Hautamäki, J., Hotulainen, R., \& Kupiainen, S. (2015). General and specific thinking skills and schooling: Preparing the mind to new learning. Thinking Skills and Creativity, 18, 53-64. DOI: 10.1016/j.tsc.2015.04.006

Vainikainen, M.-P., Hienonen, N., \& Hotulainen, R. (2017). Class size as a means of threetiered support in Finnish primary schools. Learning and Individual Differences 56, 96104. doi.org/10.1016/j.lindif.2017.05.004

Wilkinson, I., Parr, J., Fung, I., Hattie, J., \& Townsend, M. (2002). Discussion: Modelling and maximising peer effects in school. International Journal of Educational Research, 37, 521-535. DOI:10.1016/S0883-0355(03)00018-1

Yang Hansen, K., Gustafsson, J., \& Rosen, M. (2014). School Performance Differences and Policy Variations in Finland, Norway and Sweden. In Northern Lights on TIMSS and PIRLS 2011, (25-47). TemaNord 2014:528. Nordic Council of Ministers. 
Zimmer, R., \& Toma, E. (2000). Peer effects in private and public schools across countries. Journal of Policy Analysis and Management, 19, 75-92. DOI: 10.1002/(SICI)1520$6688(200024)$ 


\section{Appendices}

Appendix A

Descriptive statistics for students with and without SEN

\begin{tabular}{lcrrr}
\hline & Students with SEN $(\mathbf{n}=\mathbf{4 0 0})$ & \multicolumn{3}{c}{ Students without SEN $(\mathbf{n}=\mathbf{4}$ 968) } \\
\hline & $\boldsymbol{M}$ & $\boldsymbol{S D}$ & $\boldsymbol{M}$ & $\boldsymbol{S D}$ \\
\hline 7th grade test score & 27.58 & 15.64 & 45.74 & 21.81 \\
9th grade test score & 32.00 & 17.88 & 51.27 & 23.55 \\
Class size & 19.98 & 2.71 & 20.51 & 2.89 \\
Age & 16.01 & 0.42 & 15.90 & 0.31 \\
\hline
\end{tabular}

Note: Age is at the time of the 9 th grade assessment.

\section{Appendix B}

Descriptive statistics for regular classes with and without SEN students $(\mathrm{N}=359)$

\begin{tabular}{lcccccccc}
\hline & \multicolumn{3}{c}{ Classes with SEN $(\mathbf{n = 2 1 0})$} & \multicolumn{5}{c}{ Classes without SEN $(\mathbf{n}=\mathbf{1 4 9})$} \\
\hline & Min & Max & $\boldsymbol{M}$ & $\boldsymbol{S D}$ & Min & Max & $\boldsymbol{M}$ & $\boldsymbol{S} \boldsymbol{D}$ \\
\hline 7th grade test score & 17.53 & 70.00 & 41.72 & 8.93 & 28.93 & 77.51 & 48.21 & 10.02 \\
9th grade test score & 20.91 & 80.07 & 46.84 & 10.00 & 27.60 & 86.84 & 54.12 & 12.08 \\
Class size & 13.00 & 30.00 & 19.91 & 2.97 & 11.00 & 30.00 & 20.48 & 3.08 \\
Age & 15.25 & 17.25 & 15.89 & 0.29 & 14.58 & 16.42 & 15.91 & 0.31 \\
\hline
\end{tabular}

Note: All the descriptive statistics are class-level aggregates. Age is at the time of the 9th grade assessment.

\section{Appendix C}

Descriptive statistics for regular classes with SEN students $(n=210)$

\begin{tabular}{lcccc}
\hline & Min & Max & $\boldsymbol{M}$ & $\boldsymbol{S D}$ \\
\hline Tier 2 (number) & 0.00 & 9.00 & 1.22 & 1.24 \\
Tier 3 (number) & 0.00 & 5.00 & 0.69 & 0.80 \\
Tier 2 and 3 (number) & 0.00 & 9.00 & 1.90 & 1.27 \\
Tier 2 (\%) & 0.00 & 50.00 & 8.18 & 7.99 \\
Tier 3 (\%) & 0.00 & 30.00 & 4.64 & 5.37 \\
Tier 2 and 3 (\%) & 0.00 & 50.00 & 12.82 & 8.07 \\
\hline
\end{tabular}

Note: All the descriptive statistics are class-level aggregates. 
Appendix D

Bivariate correlation of student-level variables in Models 1-4

\begin{tabular}{rlrrr}
\hline Variable & & $\mathbf{1}$ & $\mathbf{2}$ & $\mathbf{3}$ \\
\hline $\mathbf{1}$ & 7th grade test score & & & \\
$\mathbf{2}$ & SEN status & $-.22 * * *$ & & \\
$\mathbf{3}$ & Age & $-.02 \mathrm{~ns}$ & $0.09 * * *$ & \\
\hline$* * * \mathrm{p}>0.001$, ns. non-significant & &
\end{tabular}

